\title{
Infrared Spectrometry
}

National Cancer Institute

\section{Source}

National Cancer Institute. Infrared Spectrometry. NCI Thesaurus. Code C85643.

A spectrometric method that determines the type and concentration of elements or chemicals in a sample, based upon the principle that the atoms in a sample will vibrate or rotate at a specific frequency when exposed to infrared light. 